\title{
Research Paper \\ Investigating Structural Pattern of Depression Based on Experiential Avoidance and Emotional Repression: The Mediating Role of Self-Compassion
}

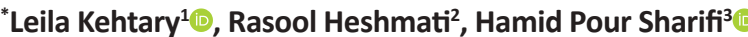

1. MA, Department of Psychology, Faculty of Education \& Psychology, University of Tabriz, Tabriz, Iran

2. PhD in Health Psychology, Assistant Professor, Department of Psychology, Faculty of Education \& Psychology, University of Tabriz, Tabriz, Iran

3. PhD in Psychology, Associate Professor, Department of Clinical Psychology, University of Social Welfare and Rehabilitation Sciences, Tehran, Iran.

\begin{tabular}{|c|c|}
\hline $\begin{array}{l}\text { Use your device to scan } \\
\text { and read the article online }\end{array}$ & detation: Kehtary L, Heshmati R, Pour Sharifi H. [Investigating Structural Pattern of Depression Based on Experiential Avoid- \\
\hline 回的部回 & ance and Emotional Repression: The Mediating Role of Self-Compassion (Persian)]. Iranian Journal of Psychiatry and Clinical \\
\hline 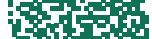 & Psychology. 2018; 24(3):284-297. http://dx.doi.org/10.32598/ijpcp.24.3.284 \\
\hline 문현 & doil": http://dx.doi.org/10.32598/ijpcp.24.3.284 \\
\hline
\end{tabular}

Funding: See Page 295

(c) Copyright: The Author(s)

Received: 07 Mar 2018

Accepted: 30 May 2018

Keywords:

Depression,

Self-compassion,

Experiential avoid-

ance, Emotional

repression

\section{A B STRACT}

Objectives The current study aims to investigate the moderating role of self-compassion in the relationship among experiential avoidance and emotional repression with depression.

Methods For the purpose of this study, 150 students from university of Tabriz were selected through convenience sampling method. Next, they were investigated in terms of self-compassion, emotional repression and depression. Beck depression inventory-II, self-compassion scale, emotion repression inventory, and experiential avoidance questionnaire were used as assessment tools. The obtained data were analyzed using Pearson correlation and path analysis.

Results Based on the results, self-compassion has significant and negative correlation with depression $(\beta=-0.75)$. Also emotional repression and experiential avoidance have positive and significant effect on self-compassion. Experiential avoidance and emotional repression have indirect effect on depression by self-compassion.

Conclusion Emotional repression; experiential avoidance and self-compassion are significant predictors of depression and default model has acceptable fitness in depression explanation.

\section{Extended Abstract}

\section{Introduction}

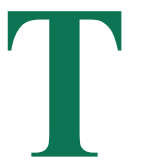

he purpose of this study was to examine the role of mediating self-esteem in the relationship between experiential avoidance and emotional suppression with depression. In depression, various mechanisms are involved; in this regard, depression involves suppressing emotions and, as a result, avoiding the intellectual and emotional experience of both inner and outer events in one direction, and in the other, you do not like yourself with compassion. It can be related because the root of depression is in the negative sense of self and escaping from experiencing internal and external experiences. Therefore, one of the structures that has been recently considered by scholars to explain the depression of depression is the concept of self-compassion.

He expresses his self-compassion as a three-component structure, including self-esteem against self-judgment, humanity versus isolation, and paradoxicalism against extremist identification. The combination of these three components is the characteristic of a person who is kind to himself. Another of the cognitive mechanisms that researchers seek to avoid depression is the avoidance of experience.

* Corresponding Author:

Leila Kehtary, MA

Address: Department of Psychology, Faculty of Education \& Psychology, University of Tabriz, Tabriz, Iran.

Tel: +98 (914) 2470568

E-mail: kehtaryleila@gmail.com 
Dealing with experience is a process that involves the extreme negative evaluation of unwanted private feelings, feelings and thoughts, and the lack of desire to experience these private events and efforts. It is deliberate to control or escape from them. According to the research, avoidance of experience leads to the maintenance and continuation of negative emotions, which leads to repeated periods of depression. In addition, some studies have shown that curative treatment reduces depressive symptoms by reducing the amount of avoidance experienced by depressed people.

\section{Method}

The purpose of this study is of fundamental type and in terms of collecting information and data is a descriptivecorrelational type. The statistical population of the study was Tabriz University students in the academic year of 2011-2012. They were selected by available sampling method. The minimum required volume for the present study was calculated based on the $\mathrm{H}$-value critical criterion $\mathrm{N}$, which was obtained for the hypothesized model based on the measured and apparent variables $(\mathrm{CN}=157.68)$.

Also, considering the minimum sample size required when variables varies between 10 and 15, the sample size should be between 200 and 400 people. Therefore, a total of 250 questionnaires were distributed among the students. 241 questionnaires were entered into the statistical analysis by deleting the defective data (incomplete or white questionnaires returned). To collect data, Beck Depression Inventory (BDI), Wittenberg's Emotional Suppression Questionnaire and self-efficacy self-esteem, as well as second-degree admission and practice scale were used.

\section{Results}

Findings showed that self-compassion has a negative and significant relationship with depression $(\beta=-0.999)$. Also emotional suppression $(\beta=0.33)$ and experience avoidance $(\beta=0.31)$ have a positive and significant effect on selfesteem. Avoiding experience and emotional suppression through self-compassion on depression has indirect effects.

\section{Discussion}

The findings showed that self-compassion in determining depression has the highest path coefficient. Correlation is self-esteem with negative depression, which indicates that with decreasing self-esteem, the rate of depression increases. The results of this study are consistent with the research by Neff, Denis et al. Also, the results of this study are consistent with Craig, Burger, Holtworth's research.
In explaining these findings, it can be said that self-sufficient self-help helps one to prevent the formation of cynical thoughts and rumination. Since rumination is a major factor in depression and other negative emotions, it can be said that reducing the amount of rumination reduces the amount of negative emotions and consequently reduces the amount of depression. Another component of self-compassion that reduces the amount of negative emotions and depression is "human sharing", which, according to this component of people who themselves have a high level, experience less negative emotions when confronted with unpleasant events by normalizing bad experiences. Thus, the individual, with the normalization of unpleasant experiences and sharing of pain and suffering, treats some kind of excitement and replaces positive emotions. Also, people who have a high level of self are less likely to put themselves in rigorous judges. People know that humans make mistakes and make mistakes, so they can more easily accept their own negative and defamatory inclinations, and they are less likely to arbitrarily discriminate.

In other findings regarding indirect paths, the results showed that emotional suppression through self-compassion has an indirect effect on depression. Based on this finding, it can be said that the process of emotional separation and shedding feelings within oneself increases the amount of self-loving depression. It seems that suppressing emotions and feelings is an important factor in increasing self-reliance, as the present study showed that emotional suppression reduces self-esteem. It seems that suppressing feelings and pouring them into oneself and not experience them with selfishness and self-reprobation, and consequently with low self-compassion, is a process that decreases the mood and increases depression.

Research findings confirm the role and importance of self-esteem as well as the avoidance of intrinsic negative thoughts and excitements, and the suppression and denial of negative emotions in depression. Therefore, the importance of interventions that emphasize the acceptance and mindfulness of depression in the treatment of depression and their goal is to reduce the avoidance of inner feelings and to increase the acceptance of emotional experiences and kindness, and can be seen from the potential clinical implications of the research.

\section{Ethical Considerations}

\section{Compliance with ethical guidelines}

After expressing the research goals for the participants, informed consent was obtained to participate in the research, 
and they were assured of the confidentiality of the information and the eligibility to participate in the research.

\section{Funding}

This research did not receive any specific grant from funding agencies in the public, commercial, or not-for profit sectors.

\section{Conflict of interest}

The authors declare no conflict of interest.

\section{Acknowledgements}

We appreciate all the participants and students of Tabriz University who helped us with this research. 


\title{
بررسى روابط ساختارى افسردكَى بر مبناى اجتناب تجربهاى و سركوبگًرى عاطفى: نقش ميانجى شفقتث بر خود
}

\author{
"ليلا كهترى'ْ، رسول حشمتى"، حميد يورشريفى"ه \\ 1- كارشناسى ارشد، كروه روانشناسى، دانشكده علوم تربيتى و روانشناسى، دانشعاه تبريز، تبريزء ايران.

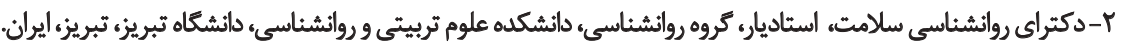

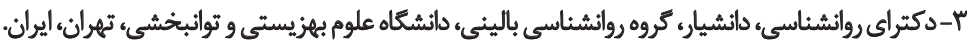

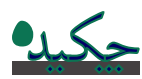

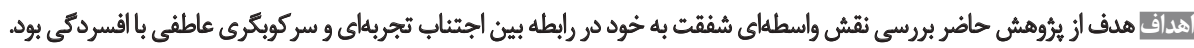

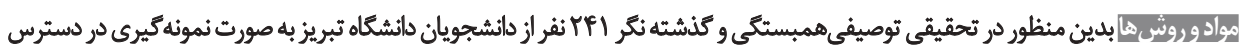

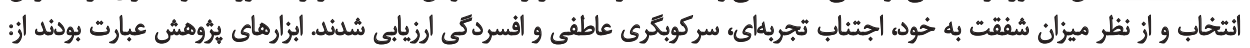

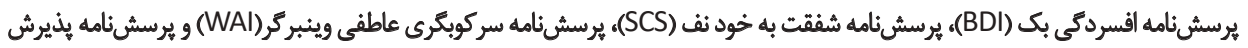

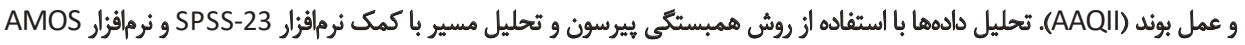
انجام شد.

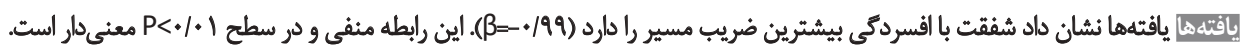

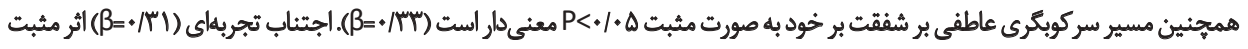

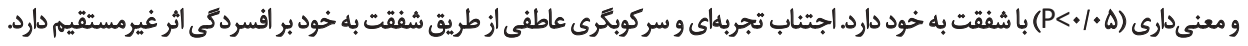

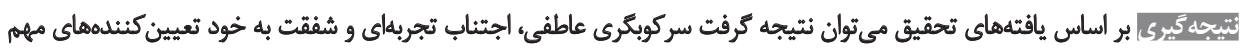

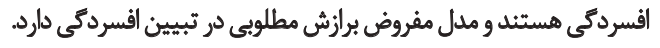

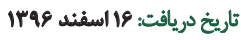

تاريخ يذيرش: 9 خرداد

كليدوازوها:

افسردكى، شفقت به

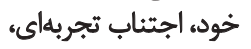
سركوبكرى عاطفي

افسردگى مي تواند با سر كوبكرى عواطف و بهتبع آن اجتنابكردن dale

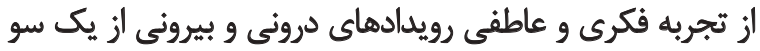

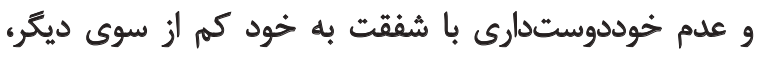

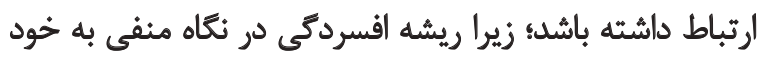

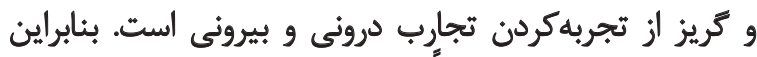

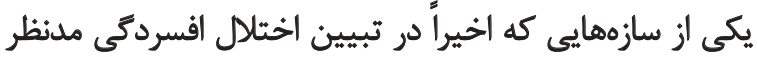

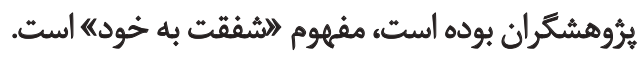

نف' شفقت به خود را سازماى سهمؤلفهاى شامل مهربانى با باني

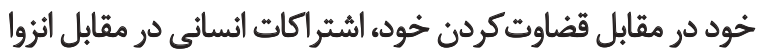

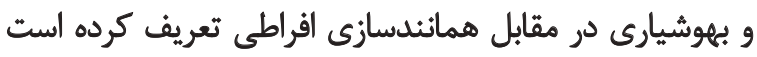

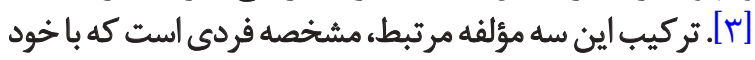

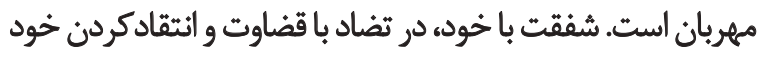

افسردمى يكى از اختلالات شايع خلقى است كه باعث

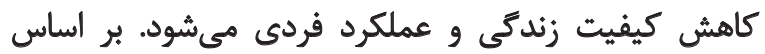

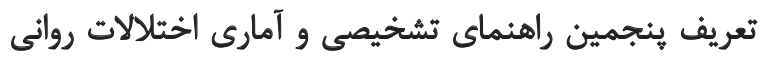

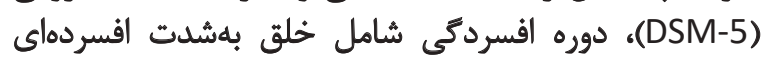

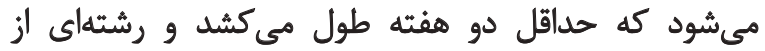

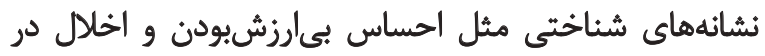

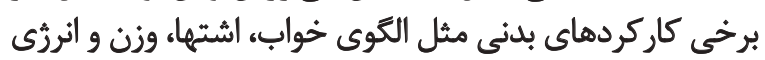

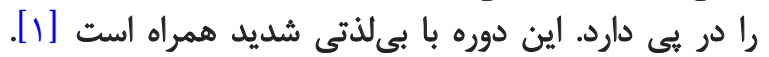

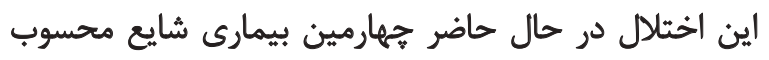

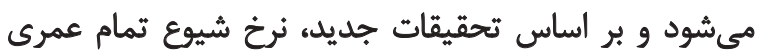

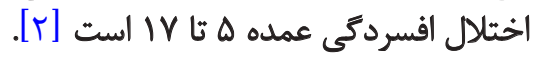
در تبيين افسردكى سازوكارهاى مختلفى دخيل است.

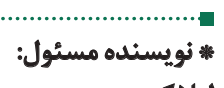

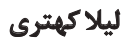

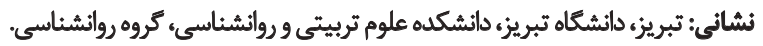

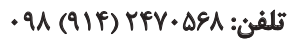
يست الكثرونيكي: kehtaryleila@gmail.com 
افسرده باعث كاهش علائم افسردكى مي شود [ • [1]. بر اين اساس، به نظر ميرسد بين اجتناب تجربهاي و افسردگى إنى

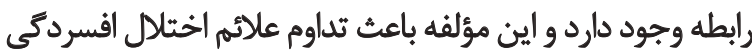

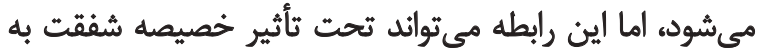

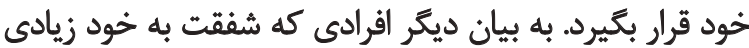

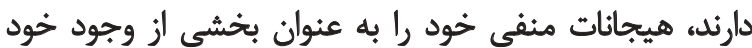

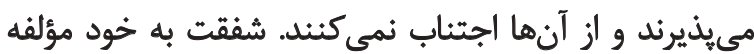

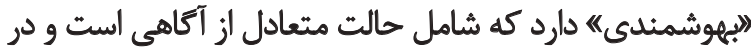

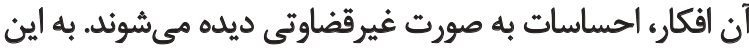

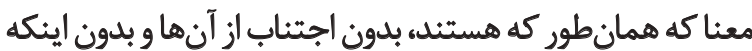

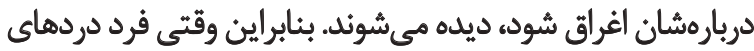

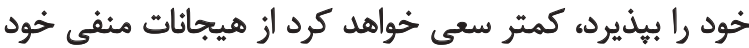

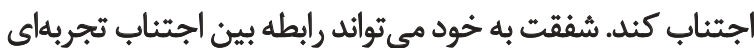

$$
\text { با افسردگ اجى را تعديل كند. }
$$

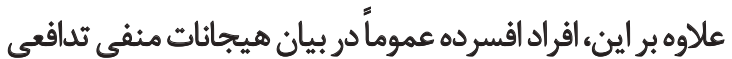

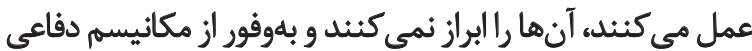

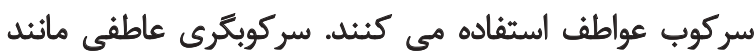

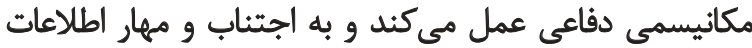

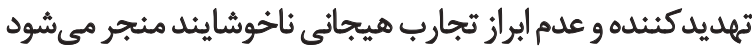

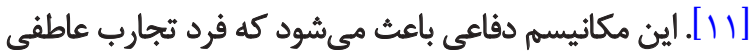

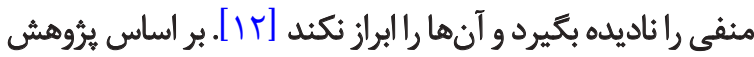

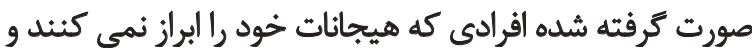

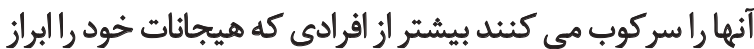

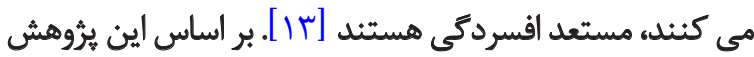

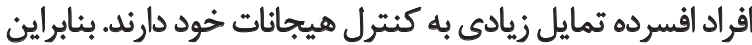

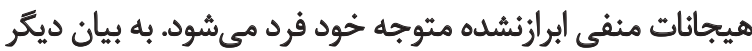

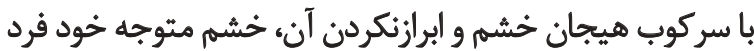

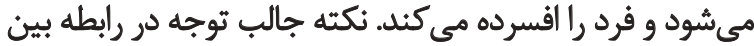

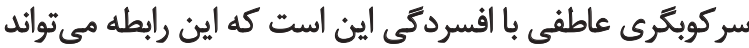

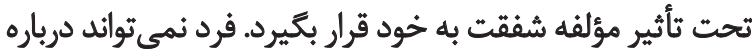

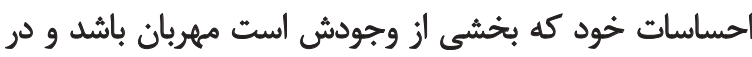

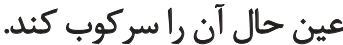

قرار دارد. اعتراف به اينكه انسانها نقص دارنده اشتباه هي كنثلد

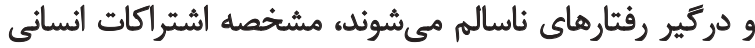

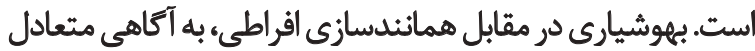

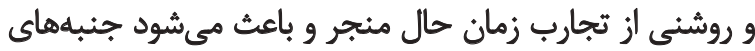

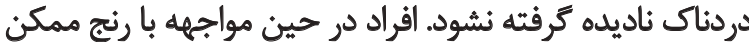

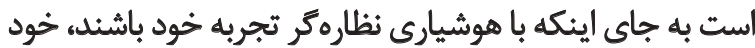

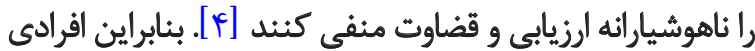

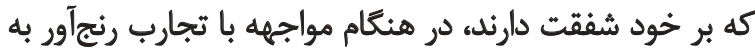

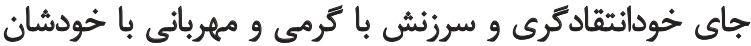

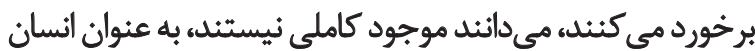

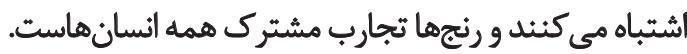

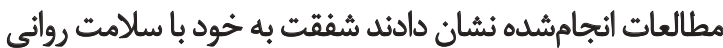

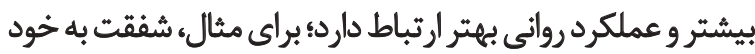

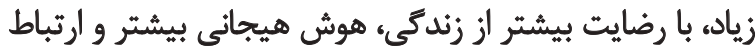

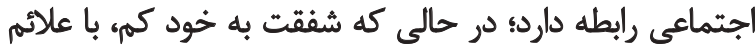

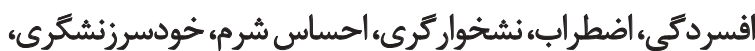

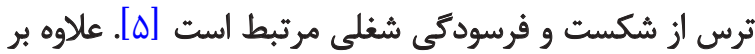

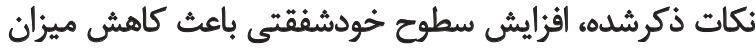

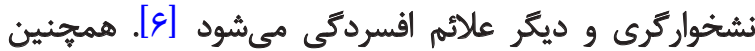

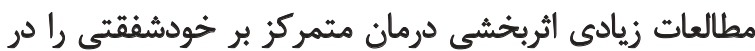

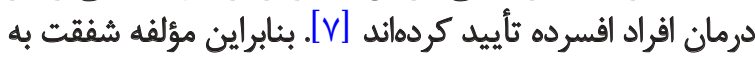
خود سازماى مرتبط با اختلال افسردكى است.

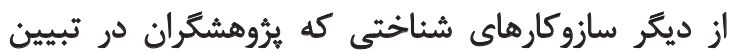

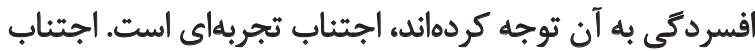

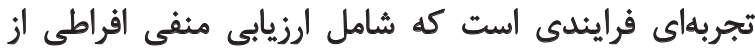

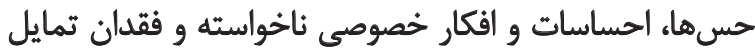

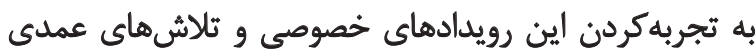

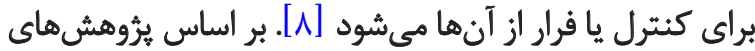

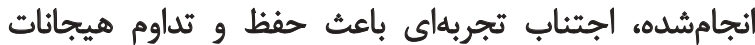

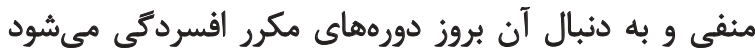

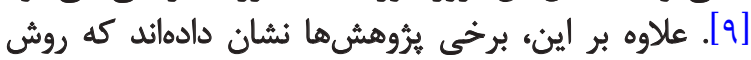

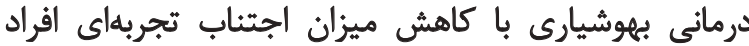

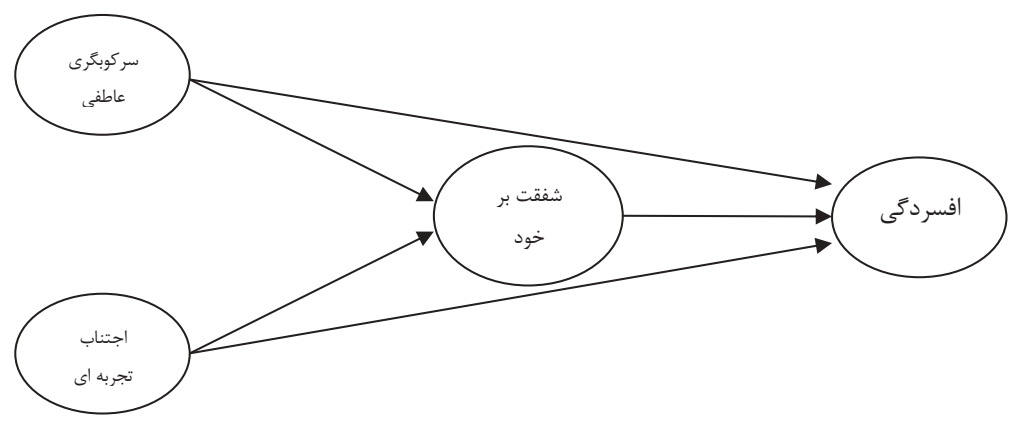




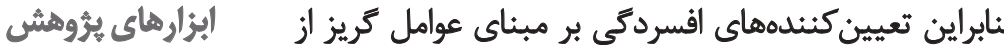

\section{يرسش نامه افسردكّ بك (BDI-II)}

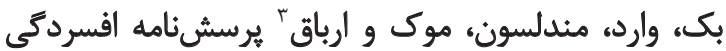

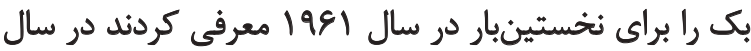

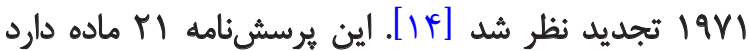

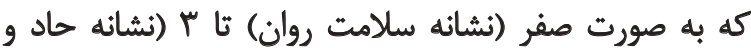

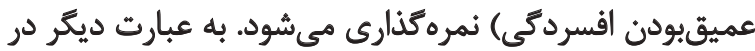

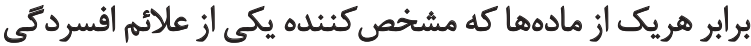

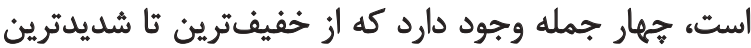

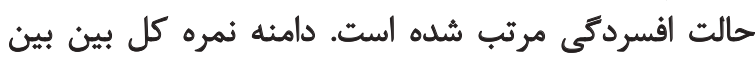

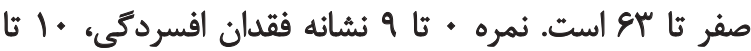

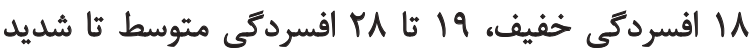

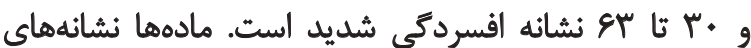

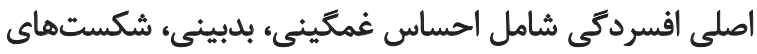

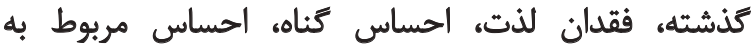

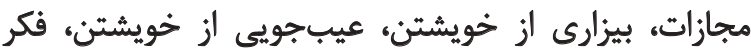

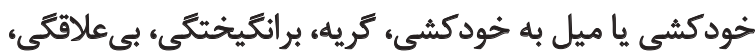

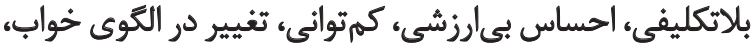

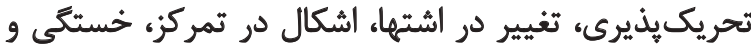

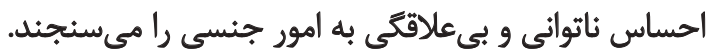

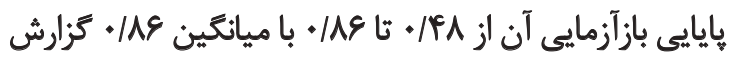

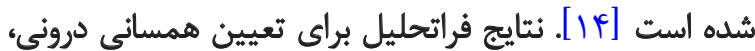

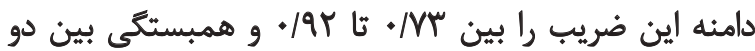

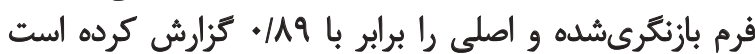

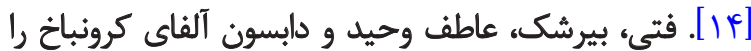

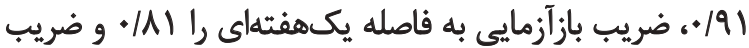

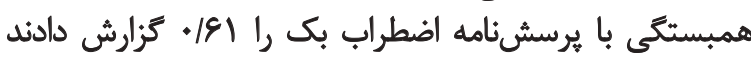

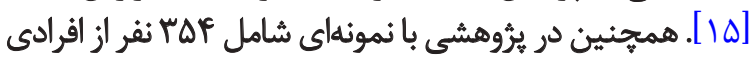

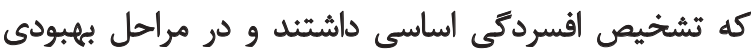

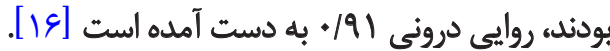

يرسش نامه يذيرش و عمل -نسخه دوم"

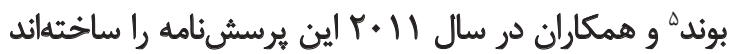

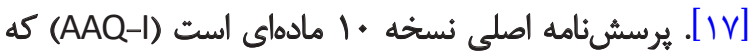

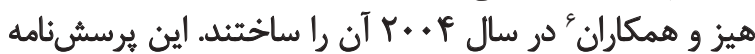

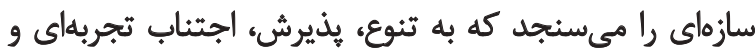

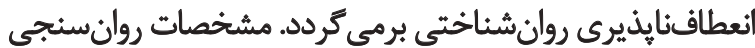

2. Beck's Depression Inventory

3. Beck, Ward, Mendelson, Mock, \& Erbaugh

4. Acceptance and Action Questionnaire-II (AAQ-II)

5. Bond

6 . Hayes et al.

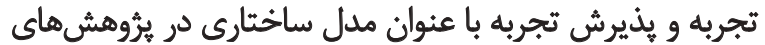

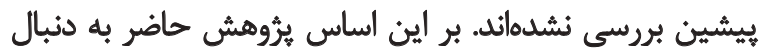

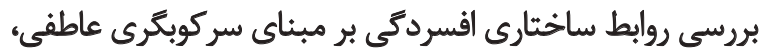

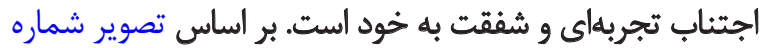

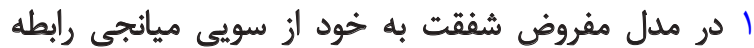

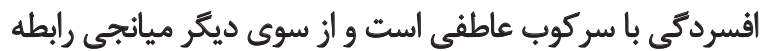

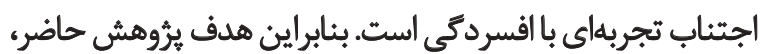

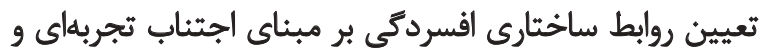

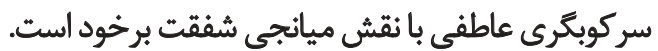

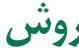

يروزوهش حاضر به لحاظ هدف، از نوع بنيادى و به لحاظ نحوه

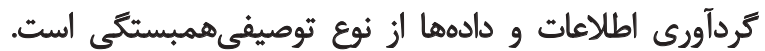

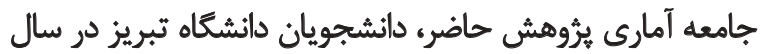

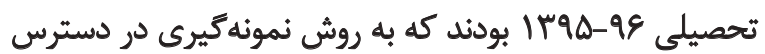

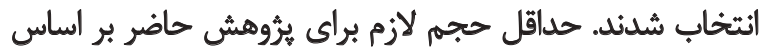

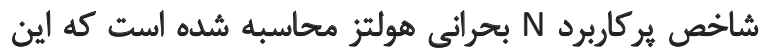
مقدار براى مدل فرضى يُروهش

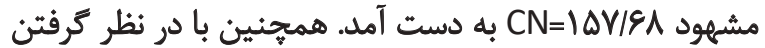

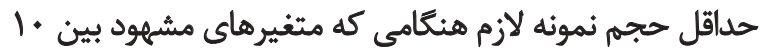

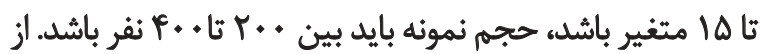

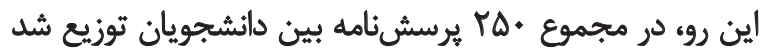

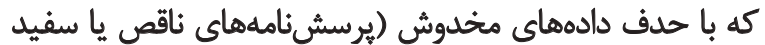

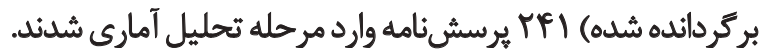

ملاكهاى ورود در اين يرؤهش عبارت بودند ازي: در سال

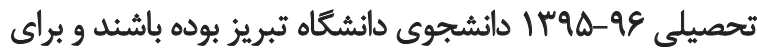

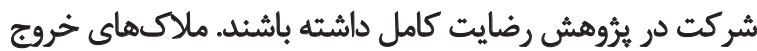

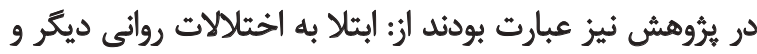

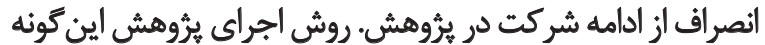

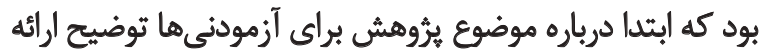

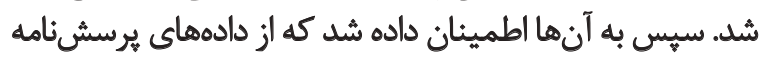

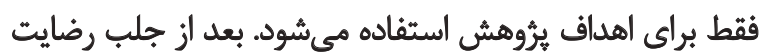

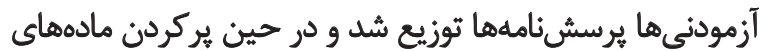

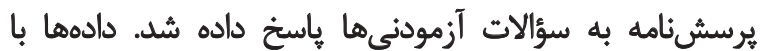

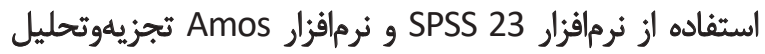

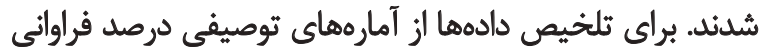

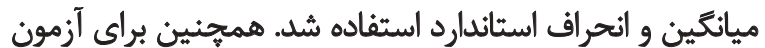

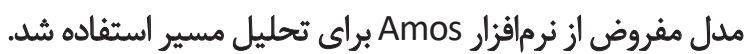


زئدكى راكزارش داد. همئين همساني درونى و ضريب تنصيف

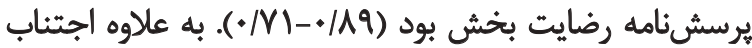

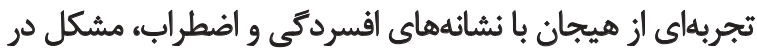

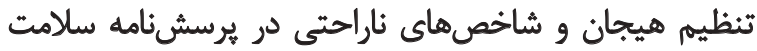

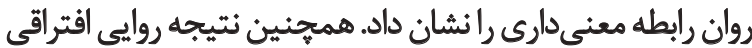

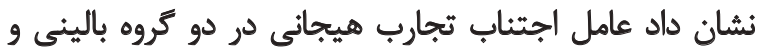

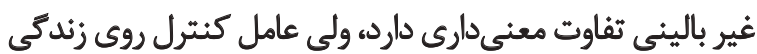
تفاوت معنى دارى در دو گروه نُشان نداد.

\section{يرسشنامه شفقت به خود"}

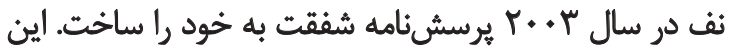

7. Self-Compassion Scale

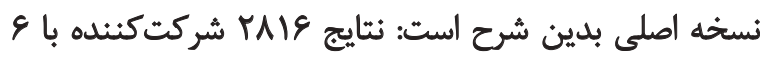

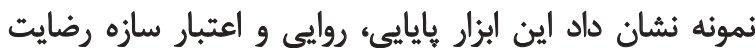

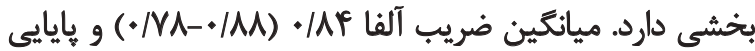

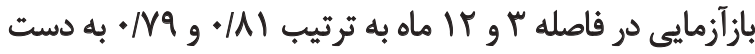

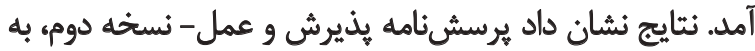

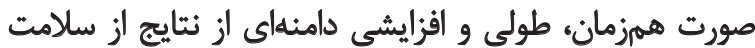

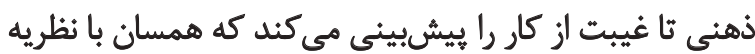

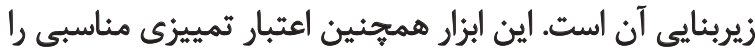

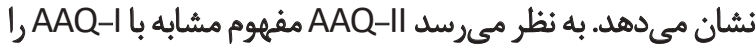

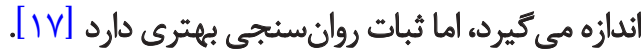
در ايران عباسى، فتى، مولودى و ضرابى مشخصات روانسنجى إنى إنى إنى

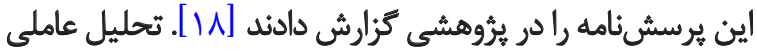

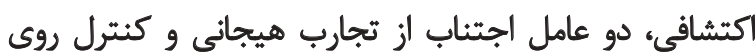

جدول ا. آماره هاي توصيفي ميانكين و انحراف استاندارد متغيرهاي يروهش

\begin{tabular}{|c|c|c|}
\hline SD & $\mathbf{M}$ & متغير \\
\hline Qpeq & $1 \pi / 4 V$ & 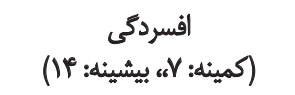 \\
\hline $11 / 49$ & $\Lambda+/ . r$ & 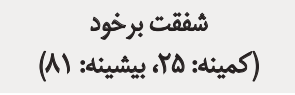 \\
\hline Ir/sa & PV/A. & 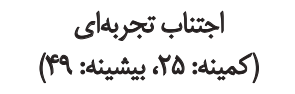 \\
\hline WET & $\mid \Delta V \cdot V$ & (كمينه: هله بيشينه: عاطفى (M) \\
\hline$M / M Y$ & IF/T & 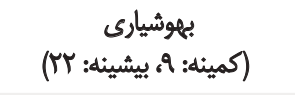 \\
\hline$r / \Delta$. & $\mid \& / \Delta P^{\circ}$ & 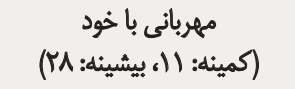 \\
\hline T/AT & १ด/। & 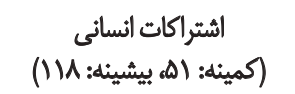 \\
\hline$r / 11$ & $11 / \Delta A$ & 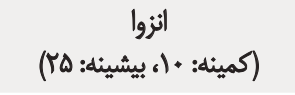 \\
\hline$r / \mu$. & $\mid r / r^{*}$ & 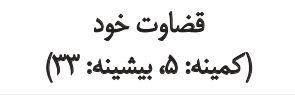 \\
\hline$r / * f^{f}$ & $1 . / M V$ & (كمينه: ه، بيشينه: بماندسازى \\
\hline$\Delta / T T$ & $1 \mathrm{r} / \mathrm{qu}$ & (كمينه: V، بيشينه: +ץ" \\
\hline $1 . / M 1$ & W/TO & 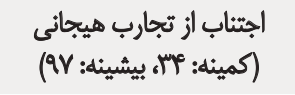 \\
\hline 1.1 .8 & E.No & تداقعى (كميثلة: Y بيشينه: VA) \\
\hline $\mathrm{II} / \mathrm{M}$ & QV/T. & 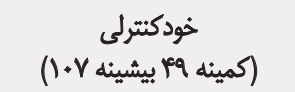 \\
\hline
\end{tabular}




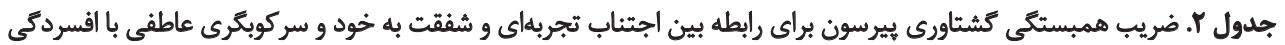

\begin{tabular}{|c|c|c|c|c|}
\hline افسردّىى & عاطقى & سركوبكرى & شفقت به خود & اجتناب تجربهاى \\
\hline & & & 1 & اجتناب تجربه اي \\
\hline & & 1 & $\cdot / R T=*$ & شفقت به خود \\
\hline & 1 &.$/ \Delta T^{\prime}$ & $-1 p q * *$ & سركوبكرى عاطفى \\
\hline 1 & & $-. / \Delta)^{m e n}$ &.$- / \Delta r^{* *}$ & افسردكى \\
\hline
\end{tabular}

$$
\text { در يُوهش حاضر AV/A به دست آمد. }
$$

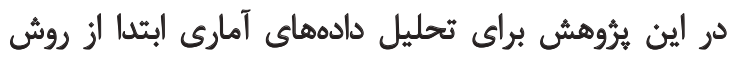

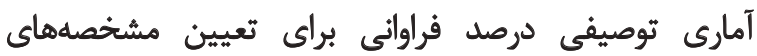

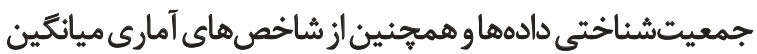

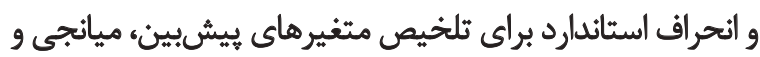

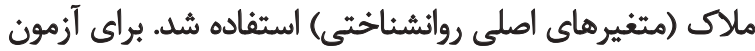

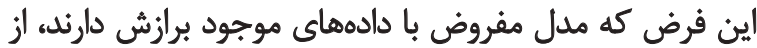

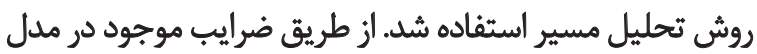

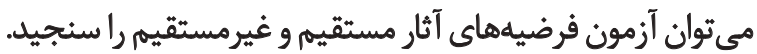

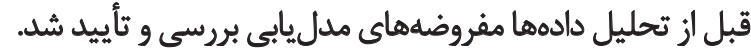

يافتهها

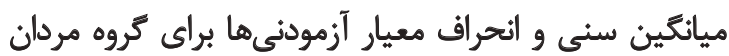
(F) كروه (I/A|

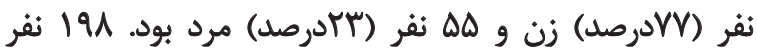

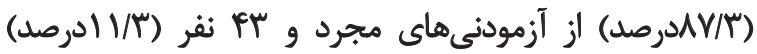

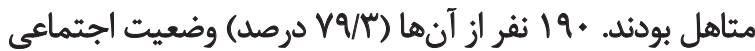

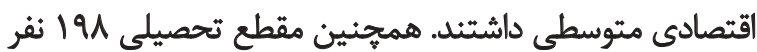

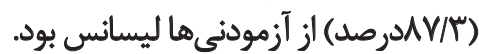
آمارههاى توصيفى ميانكين و انحراف استاندارد براى متغيرهاى

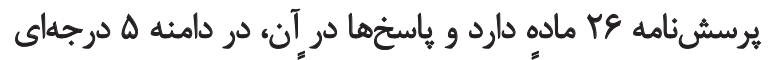

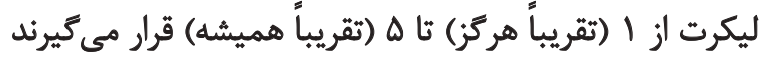

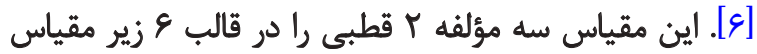

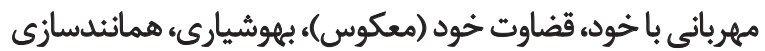

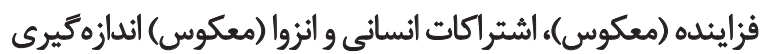

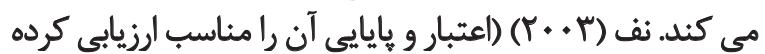

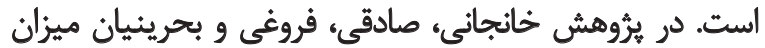

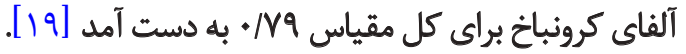

\section{يرسش نامه سركوب عاطفى يرسش نامه وينبركر ^}

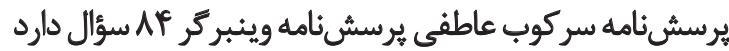

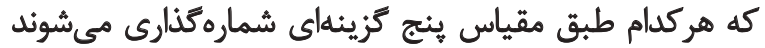

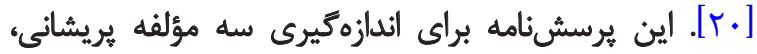

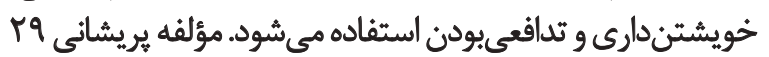

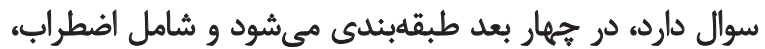

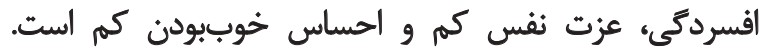

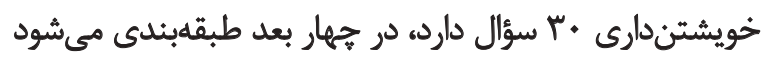

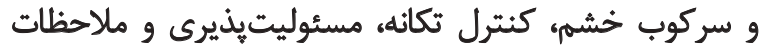

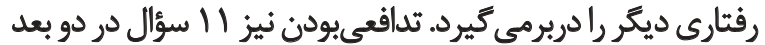

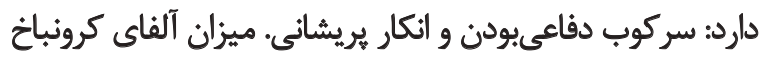

8. Weinberger Repression Questionnaire

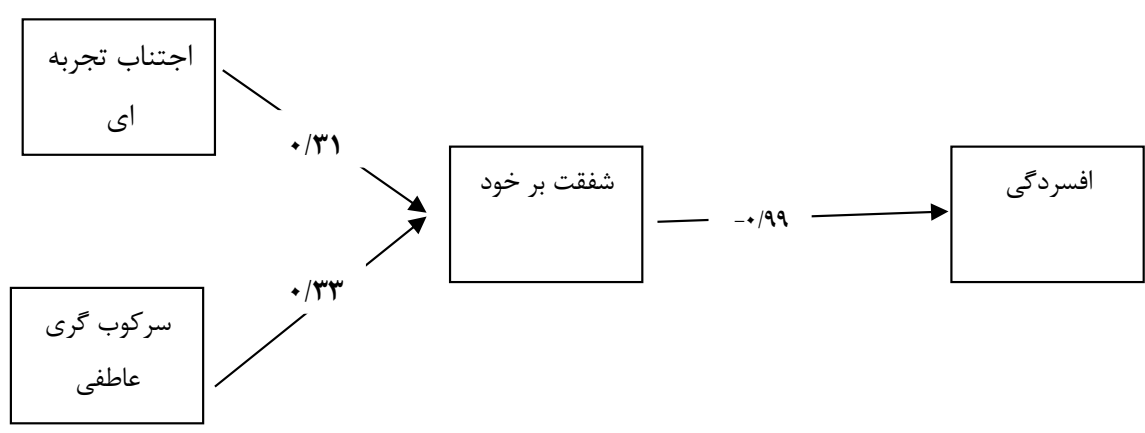


جدول ץ. مقايسه شاخصهاي برازندكى مدل بيشنهادي و اصلاحشده

\begin{tabular}{|c|c|c|c|c|c|c|c|c|}
\hline RMSEA & PNFI & CFI & TLI & IFI & AGFI & GFI & CMIN/DF & شاخصها \\
\hline$<+1+1$ & $>. / 0$. & $>.19$. & $>. / 9$. & $>.19$. & $>+1 /$. & $>.19$. & ا ثاه & بازهى قابل قبول \\
\hline$\% \vee$ & $\cdot / \Delta \Delta$ &.$/ 9 \%$ &.$/ 91$ &.$/ 94$ & /Ar &.$/ 44$ & D/Fr & مدل اصلاحشده نهايى \\
\hline برازش & برازش & برازش & برازش & برازش & برازش & برازش & برازش بر & وضعيت برازش \\
\hline
\end{tabular}

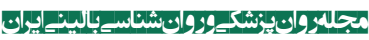

نيست، اما اين شاخص تحت تأثير حجم نمونه قرار دارد و بنابراين

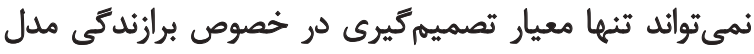

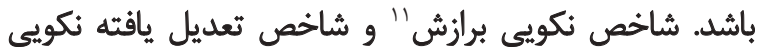

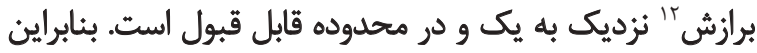

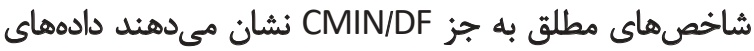
ميروهش حاضر از مدل مفهومى تحقيق حمائ تمايت مى كنيند. تمام

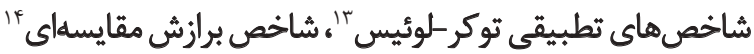

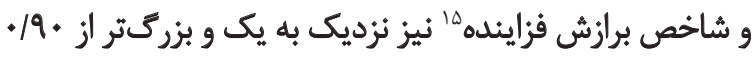

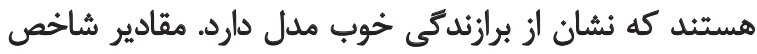

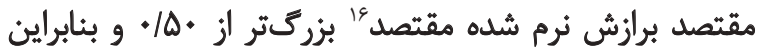

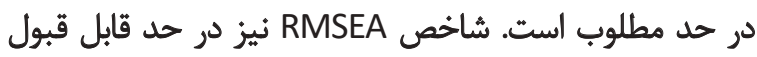

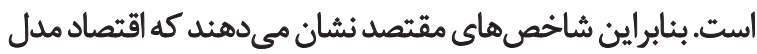

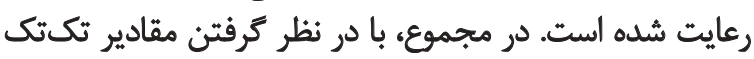

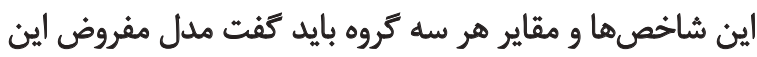
تحقيق بعد از اصلاح برازش خوبى دارد إند

$$
\text { بررسى مسيرها }
$$

\section{مسير بين متغيرها}

جدول شماره أ مسير بين متغيرها رانشان داده است. روابط

11. Goodness of Fit Index (GFI)

12. Adjusted Goodness of Fit Index (AGFI)

13. Tucker-Lewis Index (TLI)

14. Comparative Fit Index (CFI)

15. Incremental Fit Index (IFI)

16. Parsimonious Fit Indices (PNFI)

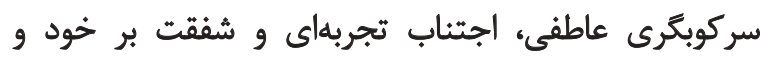

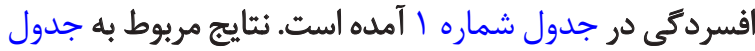

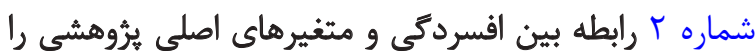

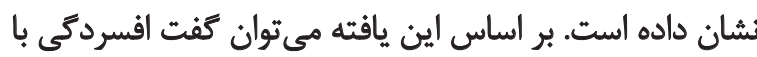

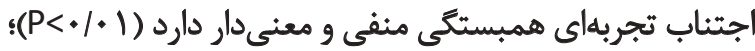

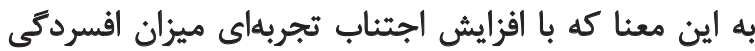

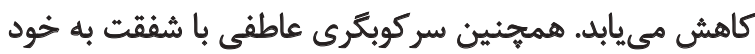

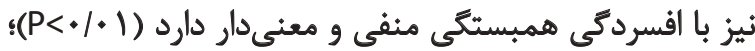

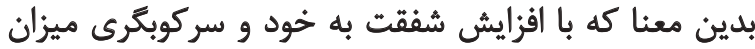
افسردگى كاهش مي يابد.

بروسى براز شدل ييشنهادى و اصلاح آن نتايج مربوط به ضرايب مسيرهاى غيرمستقيم در تصوير شماره

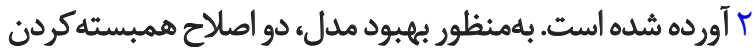

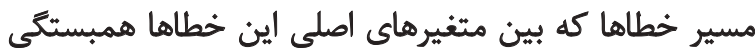

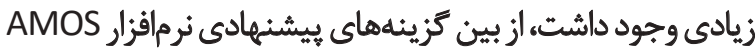

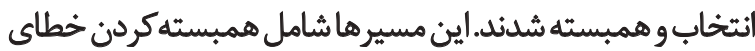

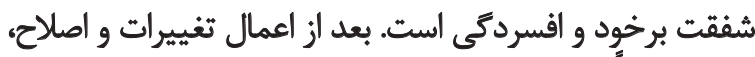

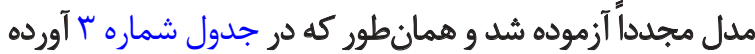
شده است، تمامى شاخصهاى براز برازش مدل الصلاحشده برازش

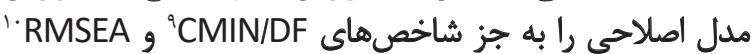
تأييد كردند.

شاخص CMIN/DF بعد از اصلاح نيز در محدوده قابل قبول

9. Minimum discrepancy/ Degree of Freedom

10. The Root Mean Square Error of Approximation (RMSEA)

جدول F. بررسى ضرايب ركّرسيونى بين متغيرهاي يُرونش

\begin{tabular}{|c|c|c|c|c|c|}
\hline آماره t & 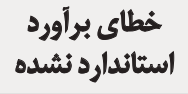 & شيارامتر استاندارد & اسثانداردود بشارامده & شُشص & مثغيرها \\
\hline PMA & .1 .8 &.$/ M I$ &.$/ \mu$ & $\beta 1$ & اجتئاب تجربه الى ـشفقت بر خود \\
\hline$r / F V^{*}$ & .1 .0 &.$/ \pi$ &.$/ 4 r$ & $\beta r$ & سركوبكرى عاطفى ـ شفقت بر خود \\
\hline$-8 / 9+\cdots$ & .111 &.$- / 99$ & $-\cdot / N \Delta$ & $\beta r$ & شققت بر خود ـافسردكى \\
\hline
\end{tabular}


جدول ه. نتايج آزمون بوت استرابّ براي مسيرهاي غيرمستقيم

\begin{tabular}{|c|c|c|c|c|c|c|}
\hline فاصله & هد بالا & حد يايين & تعد|د نمونه ميرى & هتغير ملاك & متغير ميانجي & متغير ييشبين \\
\hline.$/ 9 \Delta$ & ./TMT & $.1 . \mu$ & $1 \ldots$ & |فسردگى & شفقت بر خود & اجتناب تجربه اى \\
\hline.$/ 9 \Delta$ & - /MFA & $\%$. rq & $1 \ldots$ & افسردگى & شفقت بر خود & سركويكرى عاطفى \\
\hline
\end{tabular}

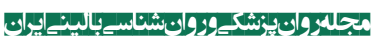

افسردكى بود. يافتهها نشان داد كل شفقت به خود در تبيين

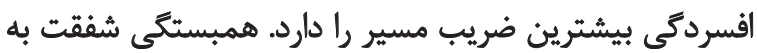

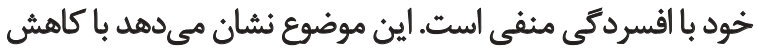

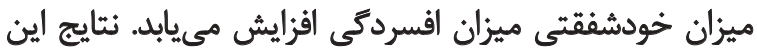

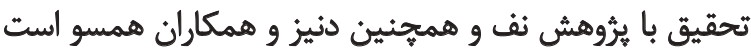

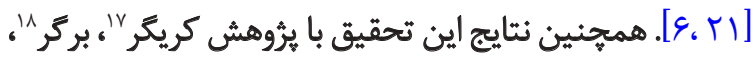

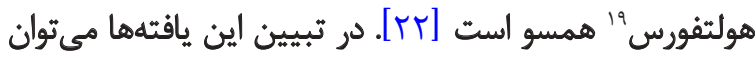
كفت بهوشيارى مرتبط با خودشفقتى به فرد كمك مي كثند از

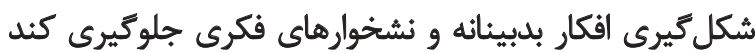

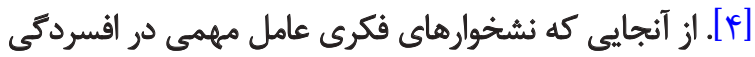

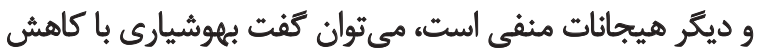

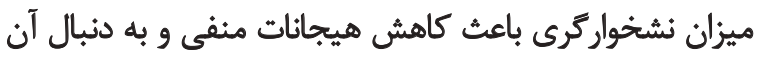

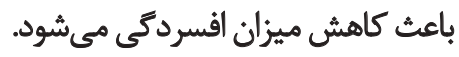

از ديكر مؤلفههاي شفقت به خود كه باعث كاهش ميزان

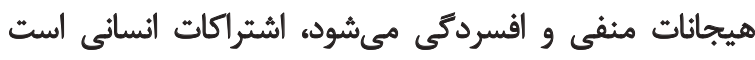

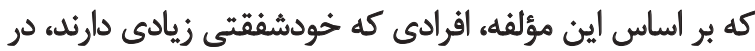

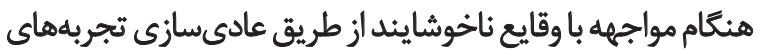

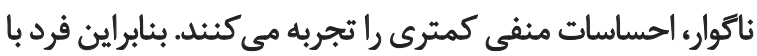

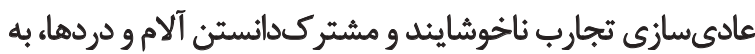

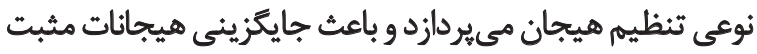

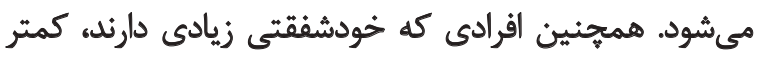

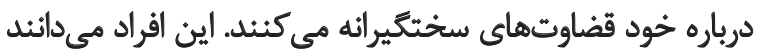

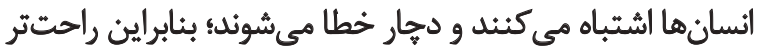

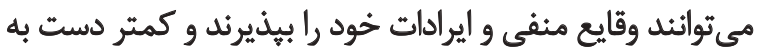

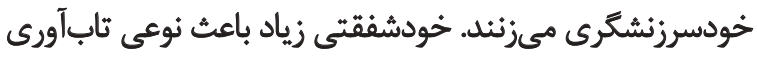

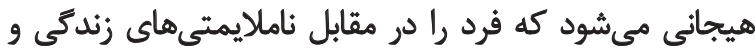
افسردكي حفظ مي كني مئن.

همجنين يافتهها نشان داد سركوبكرى عاطفى با شفقت به

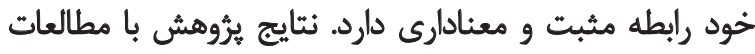

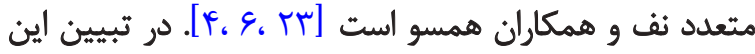
يافته ميثتوان كفت سركوبكرن فمن عواطف و ريختن احساسائي

17. Krieger

18. Berger

19. Holtforth
بين تمامي مسير هاي موجود در هدل معنى دار است. ابتدا رابطه

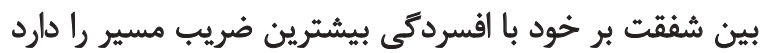

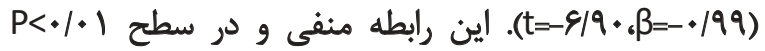

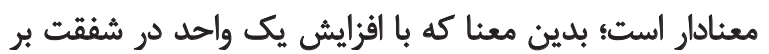

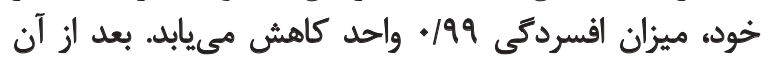
مسير رابطه سركوبكرى عاطفى بر شفقت بر خود به صورت مئ مثرديت مه

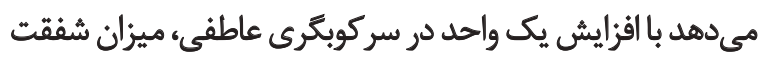

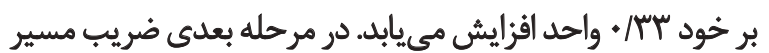

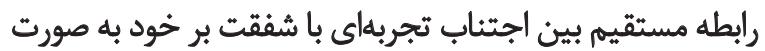

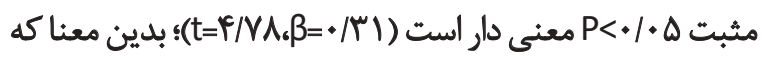

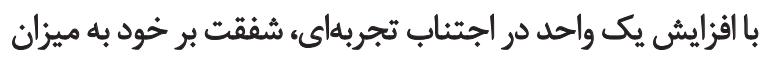

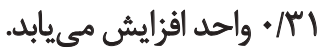

$$
\text { بروسى مسير هاى غير مستقيمي }
$$

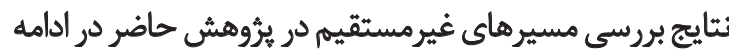

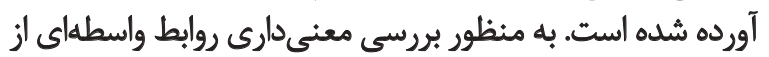

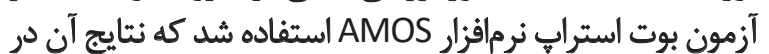
جدول شماره ها آورده شده است نرمار است

در ارتباط با ميانجي كرى شُفقت بر خود نتمايج مندرج در جدول

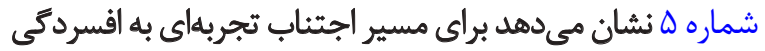

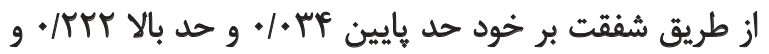

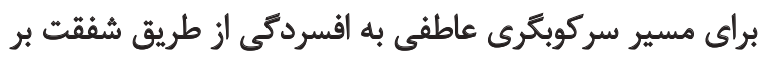

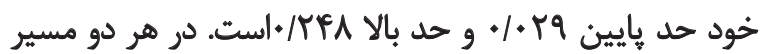

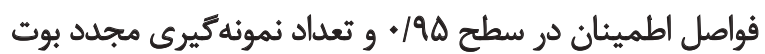

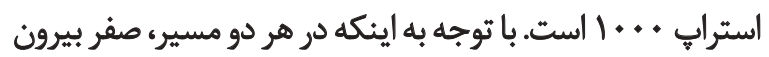

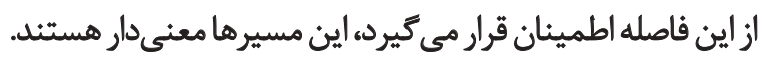

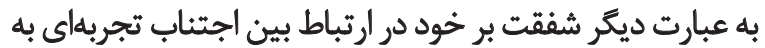
افسردكى و سركوبكرى عاطفي به افسرد

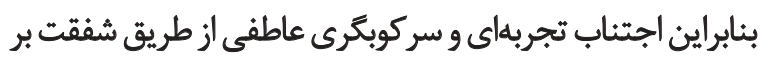

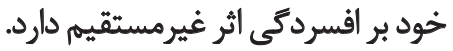

بحث

هدف از يثوهش حاضر بررنى نقش واسطهاى شفقت به

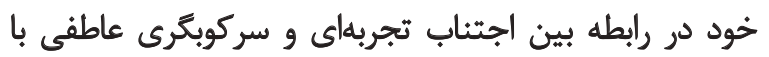




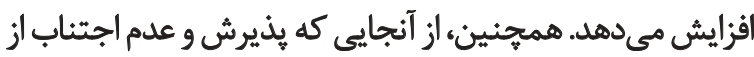

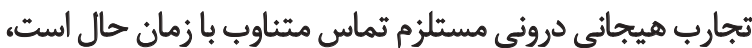

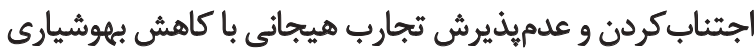

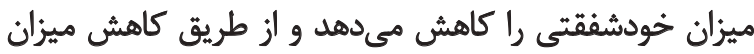

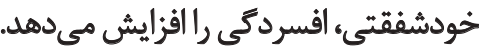

اجتناب تجربهاي يعنى تمايل به تجربه كنونى، آن كونه كه ذهن

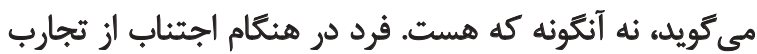

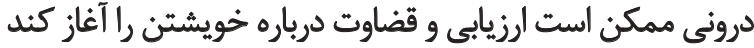

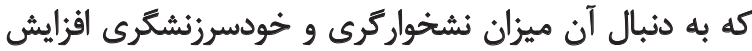

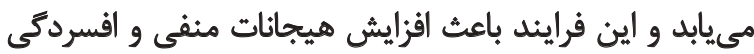

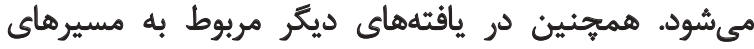

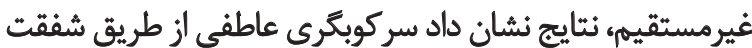

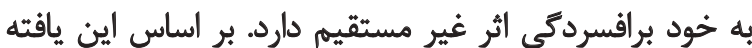

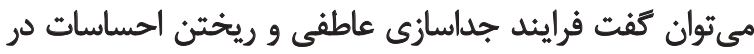

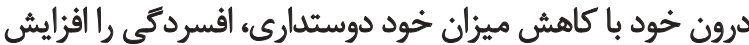

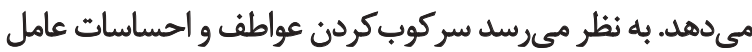

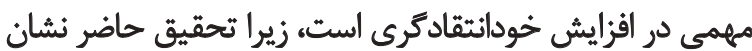

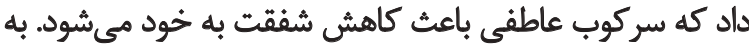

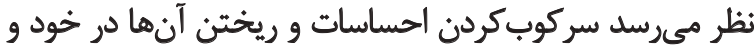

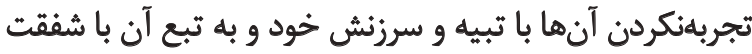
به خود كم رابطه دارد كه اين فرايند باعث كاهش خلق خلق و افزايش افسردگى مى شود. نتيجلَّيرى

يافتهاى يرؤشى، تأييدكنيده نقش و اهميت ميزان شفقت به

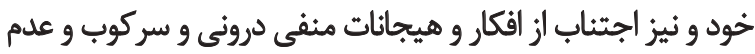

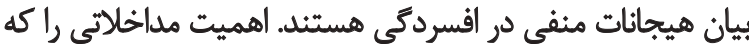

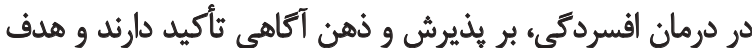

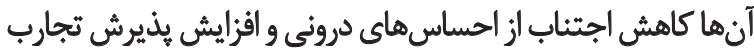

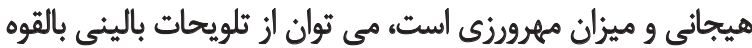
نتايج اين يثروهش در نظر مرفت ميزت

بُروهش حاضر محدوديتهايى داشت. در اين تحقيق با توجه

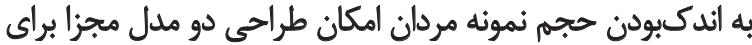

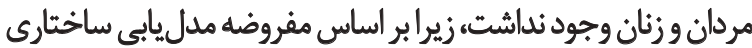

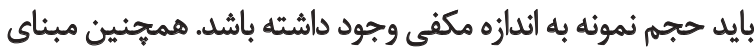

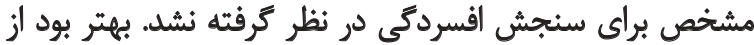

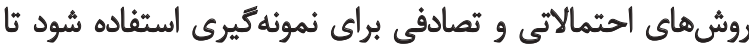

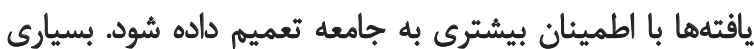

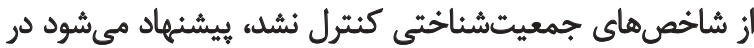

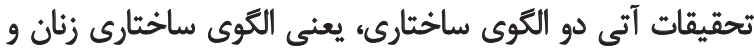

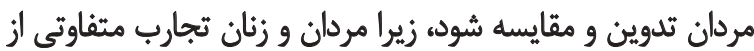

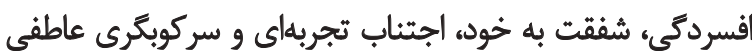

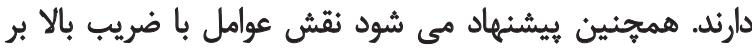

مثل خُشم، نفرت و غم در درون خُود باعث مي شُود فرد احساس

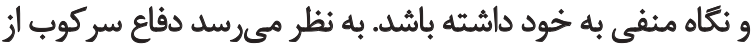

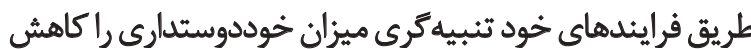

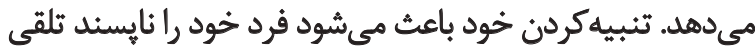

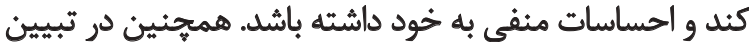

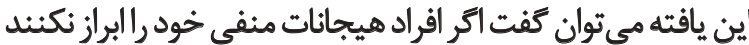

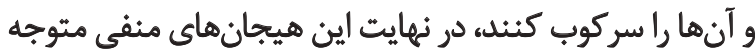

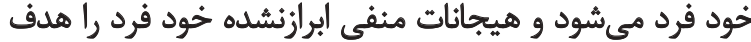

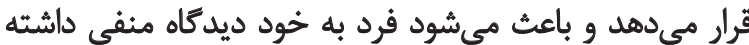
باشد و با كاهش ميزان خودشفقتى ميزان افسردكى فئ افزرايش يابد. ديكر يافتههاى بثروهش نشان داد ضريب مسير اجتناب

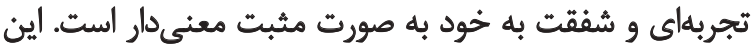

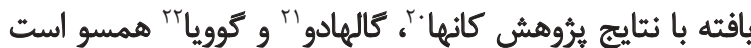

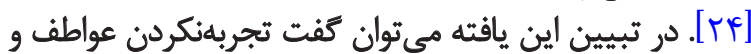

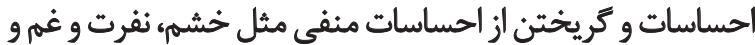

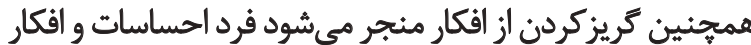

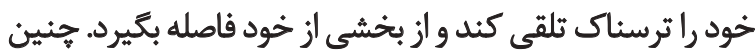

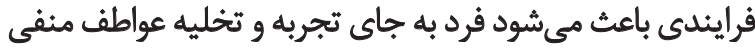

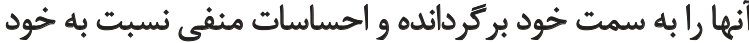

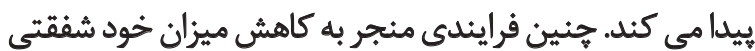

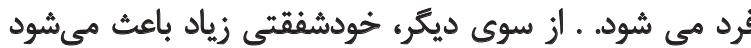

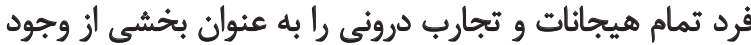

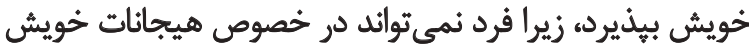

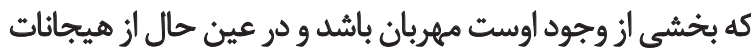

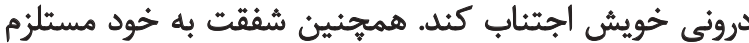

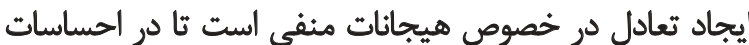

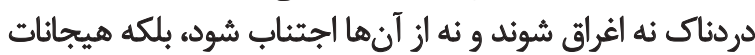
فقط به عنوان تجربه لحظه كنونى ديده مي أشوند. يافتههاى مرتبط با مسيرهاى غيرمستقيه نشان داد اجتناب

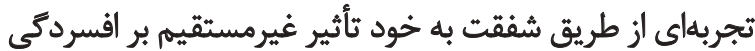

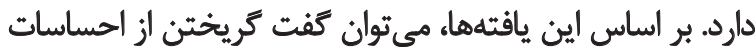

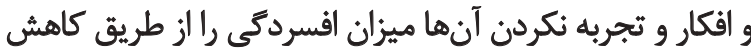

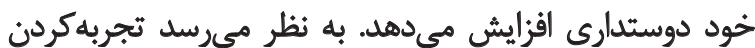

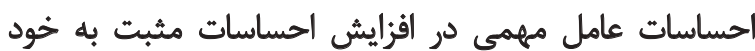

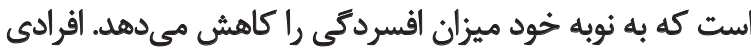

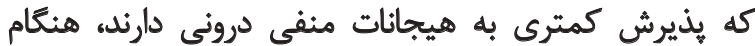

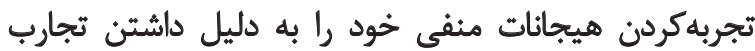

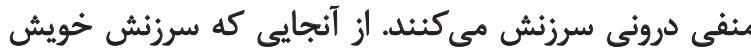

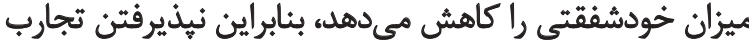

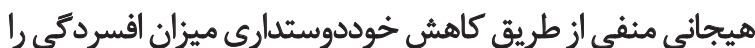

20. Conha

21. Galhardo

22. Gouveia 


$$
\text { مالفردى نيز در مدليابى عوامل مؤثر بر افسردىى بررسى شود. }
$$

$$
\text { ييروى از اصول اخلاق يخوهش }
$$

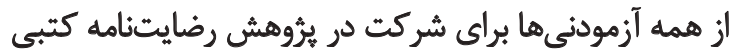

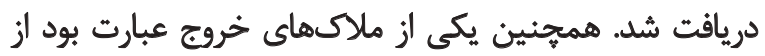

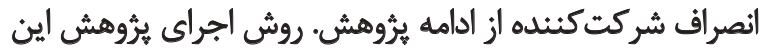

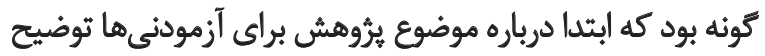

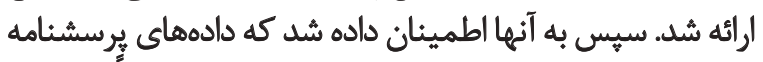
فقط براى اهداف يُروهشى بوده و اطلاعات آنها كاملاً محرمانه

$$
\text { خواهد بود. }
$$

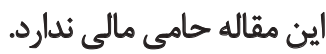

$$
\text { تضاد منافع }
$$

نويسندكان مقاله حاضر هيج كونه تضاد منافعى درباره اين

$$
\text { مقاله ندارند. - مقان }
$$

$$
\text { سِّاسگَزارى }
$$

از تمامي شركت كنيندكان كه ما رادر اين اجراي و تكميل اين

$$
\text { يرؤش يارى كردند، تشكر مى كنيهم. }
$$




\section{References}

[1] The American Psychiatric Association. Diagnostic and statistical Manual of mental disorder fifth edition. Virginia; 2013

[2] Sadock B, Sadock V. Kaplan \& Sadock's Synopsis of Psychiatry: Behavioral sciences/clinical psychiatry. Philadelphia: Lippinottwiliams and Wilkins; 2014.

[3] Neff KD. The development and validation of a scale to measure self-compassion. Self and identity. 2003; 2(3):223250. [DOI:10.1080/15298860309027]

[4] Neff KD. The role of self-compassion in development: A healthier way to relate to oneself . Human development. 2009; 52(4):211-4. [DOI:10.1159/000215071] [PMID] [PMCID]

[5] Neff KD. Self-compassion, self-esteem, and well-being. Social and personality psychology compass. 2011; 5(1):1-12 [DOI:10.1111/j.1751-9004.2010.00330.x]

[6] Neff KD. Self-compassion:An alternative conceptualization of a healthy attitude toward oneself. Self and Identity. 2003; 2(2):85- 101. [DOI:10.1080/15298860309032]

[7] Gillbert P, Procter S. Compassionate mind training for people with high shame and self-criticism: Overview and pilot study of a group therapy approach. Clinical Psychology and Psychotherapy. 2006; 13:353-379. [DOI:10.1002/cpp.507]

[8] Kashdan TB, Barrios V, Forsyth JP, Steger MF. Experiential avoidance as a generalized psychological vulnerability: Comparisons with coping and emotion regulation strategies. Behaviour Research and Therapy. 2006; 44(9):1301-2. [DOI: 10.1016/j.brat.2005.10.003] [PMID]

[9] Biglana A, Gaua JG, BackenJones L, Hinds E, Rusby JC, Cody C, Sprague J. The role of experiential avoidance in the relationship between family conflict and depression among early adolescents. Journal of Contextual Behavioral Science. 2015; 4(1):30-36. [DOI:10.1016/j.jcbs.2014.12.001]

[10] Schut DM.; Boelen PA. The relative importance of rumination, experiential avoidance and mindfulness as predictors of depressive symptoms. Journal of Contextual Behavioral Science. 2017; 6(1):8-12. [DOI:10.1016/j.jcbs.2016.11.008]

[11] Weinberger DA, Schwartz GE. Distress and restraint as superordinate dimensions of self-reported adjustment: A typological perspective. Journal of Personality. 1990; 58(2):381-417. [DOI:10.1111/j.1467-6494.1990.tb00235.x] [PMID]

[12] Garssen B. Repression: Finding our way in the maze of concepts. Journal of Behavioral Medicine. 2007; 30(6):47181. [DOI:10.1007/s10865-007-9122-7] [PMID] [PMCID]

[13] Beutler LE, Daldrup R, Engle D, Gues P, Corbishley A, Meredith KE. Family dynamics and emotional expression among patients with chronic pain and depression. Pain. 1988; 32(1):65-72. [DOI:10.1016/0304-3959(88)90024-3]

[14] Beck AT, Steer RA, Carbin MG. Psychometric properties of the beck depression inventory: Twenty-five years of evaluation. Clinical Psychology Review. 1988; 8(1):77-100. [DOI:10.1016/0272-7358(88)90050-5]
[15] Fata L, Birashk B, Atefvahid M K, Dabson K S. [Meaning assignment structures schema, emotional states and cognitive processing of emotional information: Comparing two conceptual frameworks (Persian)]. Iranian Journal of Psychiatry \& Clinical Psychology. 2005; 11(3):312-26.

[16] Dabson KS, Mohammadkhani P. [Psychometrics Characteristic of Beck Depression Inventory-II in Patients with Magor Depressive Disorder (Persian)]. Archives of Rehabilitaion. 2007; 8(29):82-8.

[17] Bond FW, Hayes SC, Baer RA, Canpenter KM, Guenole N, Orcutt HK, Walts T, Zettle RD. Preliminary psychometric properties of the acceptance and action questionnair-ll: A revised measure of psychological inflexibility and experiential avoidance. Behavior Therapy. 2011; 42(4):676-88. [DOI:10.1016/j.beth.2011.03.007] [PMID]

[18] Abbasi E, Fati L, Molodi R, Zarabi H. [Psychometric properties of Persian Version of Acceptance and Action Questionnaire -II. Cognitive models (Persian)]. Journal of Psychological Models and Methods. 2013; 2(10):65-80.

[19] Khanjani S, Foroughi AA, Sadghi K, Bahrainian SA. [Psychometric properties of Iranian version of self-compassion scale (short form) (Persian)]. Pejouhandeh. 2016; 21(5):282-9.

[20] Pagt V, Consoli SM, Carton S. French translation and validation of the weinberger repression questionnaire. France: Masson Editeur; 2010

[21] Deniz ME, Sumer AS. The evaluation of depression, anxiety and stress in university students with different selfcompassion levels. Egitimve Bilim. 2010; 35(158):115.

[22] Krieger T, Berger T, Holtforth MG. The relationship of self-compassion and depression: Cross-lagged panel analyses in depressed patients after outpatient therapy. Journal of affective disorders. 2016; 202:39-45. [DOI:10.1016/j jad.2016.05.032] [PMID]

[23] Neff KD; Rude SS; Kirkatrick KL. An examination of selfcompassion in relation to positive psychological functioning and personality traits. Journal of Research in Personality. 2007; 41(4):908-16

[24] Conha M, Galhardo A, Pinto-Gouveia J. Experiential avoidane, self-compassion, self-judgment and coping styles in infertility. Sexual \& Reproductive Healthcaree. 2016; 10:41-47. [DOI:10.1016/j.srhc.2016.04.001] [PMID] 
